\title{
Kulak Akıntı Kültürlerinden İzole Edilen Pseudomonas aeruginosa Suşlarının Antibiyotik Duyarlılıklarının Değerlendirilmesi
}

\author{
Evaluation of Antibiotic Susceptibility of Pseudomonas aeruginosa Strains \\ Isolated from Ear Flow Cultures
}

Sevil ALKAN ÇEVIKER ${ }^{1}$, Özgür GÜNAL ${ }^{1}$, Dursun Mehmet MEHEL ${ }^{2}$, Abdulkadir ÖZGÜR²,

Süleyman Sırrı KILIÇ ${ }^{1}$

\begin{abstract}
$\overline{1} 1$ Sağlık Bilimleri Üniversitesi Samsun Eğitim Araştırma Hastanesi, Enfeksiyon Hastalıkları ve Klinik Mikrobiyoloji Kliniği, Samsun ¿lurklye

2 Sağlık Bilimleri Üniversitesi Samsun Eğitim Araştırma Hastanesi, Kulak Burun Boğaz Hastalıkları Kliniği, Samsun, Türkiye
\end{abstract}

Geliş tarihi: 27.05.2019 Kabul tarihi: 10.12.2019 DOI: 10.17517 ksutfd.570602

\begin{abstract}
Özet
Amaç: Orta kulak ve mastoidin kronik enflamasyonu ile karakterize olan kronik süpüratif otitis media (KSOM) sıklıkla akıntı ve işitme kaybı ile belirti verir. Süpürasyondan sıklıkla sorumlu olan bakteriyal etken Pseudomonas'lardır. Artan direnç oranları nedeniyle tedavi güçlügüne ve klinik yanıtsızlığa neden olabilen Pseudomonas'ların önemi giderek artmaktadır. Bu çalışmada, hastanemiz Kulak Burun Boğaz Hastalıkları Kliniği’nde KSOM tanısı konulan ve dış kulak yolundan alınan kültürlerde üreyen Pseudomonas aeruginosa cinsi bakterilerin antibiyotik duyarlılıklarının araştırılması ve benzer çalışmalarla kıyaslamaları amaçlandı.

Gereç ve Yöntemler: Ağustos 2015-Ağustos 2018 tarihleri arasında hastanemiz Kulak Burun Boğaz Hastalıkları Kliniği’nde alınan kulak akıntı kültürlerinden izole edilen Pseudomonas aeruginosa suşlarının antibiyotik duyarlılıklarının araştırıldı. Üreyen mikroorganizmaların tanısında rutin mikrobiyolojik yöntemler kullanıldı.

Bulgular: Çalışma döneminde 73 hastadan kulak kültürü gönderildiği ve bunların 34'ünde (\%46.5) Pseudomonas aeruginosa üremesi olduğu saptandı. Bu hastaların 19 (\%55.8)'u erkek, 15 (\%44.2)'i kadın, yaş ortalaması 44.9 (15-69) idi. Pseudomonas aeruginosa suşlarının antibiyogramları incelendiğinde; en duyarlı oldukları antibiyotik sınıfının kolistin (\%100), karbapenem grubundan imipenem (\%82.3) ve meropenem (\%82.3) olduğu; en fazla antibiyotik direncinin ise netilmisin (\%52.9), piperasilin (\%41.2), piperasilin/tazobaktama (\%41.2) ve levofloksasine (\%41.2) karşı olduğu saptandı. Tedavide en sık kullanılan antibiyotik olan siprofloksasine karşı \%61.7 oranında duyarlı olduğu belirlendi.

Sonuç: KSOM'da etken patojenin duyarlılık profilleri zaman içerisinde değişiklik gösterebileceğinden, komplikasyon gelişme riskinin azaltılması, zaman ve maliyet kaybının en aza indirgemesi amaçları ile antibiyotik duyarlılıkları takip edilmeli ve antibiyotik tedavileri güncel verilere göre düzenlenmelidir.
\end{abstract}

Anahtar kelimeler: Kulak Akıntı Kültürü; Pseudomonas aeruginosa; Antibiyotik Duyarlılıkları

\begin{abstract}
Objective: Chronic suppurative otitis media (KSOM), which is characterized by chronic inflammation of the middle ear and mastoid, often presents with signs of discharge and hearing loss. In sweeping, often responsible bacterial class is Pseudomonas. Due to the increased resistance rates, the importance of Pseudomonas, which can lead to treatment difficulties and clinical failure, becoming more prominent. The aim of this study was to investigate the antibiotic susceptibility of Pseudomonas aeruginosa which was isolated from ear flow cultures and to make comparisons with similar studies.

Materials and Methods: Between August 2015 and August 2018, we investigated the antibiotic susceptibility of Pseudomonas aeruginosa strains in the ear discharge cultures at the Otorhinolaryngology Clinic of our hospital. Routine microbiological methods were used for the diagnosis of microorganisms.

Results: Ear culture was sent from 73 patients during the study period and 34 of them (46.5\%) had Pseudomonas aeruginosa growth. Of these patients, $19(55.8 \%)$ were male, 15 (44.2\%) were female, and the mean age was 44.9 (15-69). When antibiogram of Pseudomonas aeruginosa strains were examined; the most sensitive class of antibiotics were colistin (100\%), imipenem (82.3\%) and meropenem (82.3\%) from carbapenem group; the highest resistance was against netilmicin (52.9\%), piperacillin (41.2\%), piperacillin / tazobactam (41.2\%) and levofloxacin (41.2\%). Ciprofloxacin sensitivity, which is the most frequently used antibiotic in the treatment, was $61.7 \%$.

Conclusion: Since the susceptibility profiles of the causative pathogen in CSOM may change over time, antibiotic susceptibility should be monitored and antibiotic therapies should be adjusted according to the current data in order to reduce the risk of complication and to minimize the loss of time and cost.
\end{abstract}

Keywords: Ear Flow Culture; Pseudomonas aeruginosa; Antibiotic Susceptibility.

Yazışma Adresi: Sevil ALKAN ÇEVİKER Sağlık Bilimleri Üniversitesi Samsun Eğitim Arastırma Hastanesi, Enfeksiyon Hastalıkları ve Klinik Mikrobiyoloji Kliniği, Samsun. NTürkiye Mail: s-ewil@hotmail.com Tlf:05066873768

ORCID No (Sirasiyla):0000-0003-1944-2477, 0000-0002-7744-4123, 0000-0002-5613-3393, 0000-0002-6155-5988, 0000-0002- 


\section{GİRIŞ}

Orta kulak ve mastoidin kronik enflamasyonu ile karakterize olan kronik süpüratif otitis media (KSOM) sıklıkla akıntı ve işitme kaybı ile belirti verir. Süpürasyondan sıklıkla sorumlu olan ajan Pseudomonas cinsi bakterilerdir (1). Doğada yaygin olarak bulunan, suda ve nemli ortamlarda rahatça üreyebilen Gram negatif, hareketli, sporsuz, kapsülsüz, aerob, çevre koşullarına kolaylıkla adapte olabilen basiller olan Pseudomonas cinsi bakteriler, bazen sağlıklı insanlarda normal flora üyesi olarak da saptanabilir. Bu bakteriler yumuşak doku enfeksiyonlarından sepsise kadar birçok klinik tabloya neden olabilmektedir $(2,3)$. Kronik süpüratif otitis mediada tedavinin amac1, enfeksiyonu eradike etmek, komplikasyonları önlemek, kulak zarının tamirini sağlamak ve işitmeyi düzeltmektir. Medikal tedavi enfeksiyonu kontrol etmek ve akıntıyı önlemek amacıyla yapılır. Kulak zarının tamiri ve işitmenin düzeltilmesi ise için ise çoğunlukla cerrahi tedavi gerekir. Hastalık erken dönemde tanınmazsa veya uygun tedavisi yapılmazsa ciddi komplikasyonlar gelişebilir (1). Artan direnç oranları nedeniyle tedavi güçlügüne ve klinik yanıtsızlığa neden olabilen Pseudomonas cinsi bakterilerin önemi giderek artmaktadır (2-4).

Bu çalışmada, hastanemiz Kulak Burun Boğaz Hastalıkları Kliniği’nde KSOM tanısı konulan ve dış kulak yolundan alınan kültürlerde üreyen Pseudomonas aeruginosa cinsi bakterilerin antibiyotik duyarlılıklarının araştırılması ve benzer çalışmalarla kıyaslamaların yapılması amaçlandı.

\section{GEREÇ VE YÖNTEMLER}

Ağustos 2015-Ağustos 2018 tarihleri arasında Samsun Eğitim Araştırma Hastanesi Kulak Burun Boğaz Hastalıkları Kliniği'nde KSOM tanısı konulan ve bu hastaların dış kulak yolundaki akıntıdan alınan materyallerin kültüründe üreyen P.aeruginosa cinsi bakterilerin antibiyotik duyarlılıklarının araştırılması amacıyla bu çalışma yapıldı. Mikrobiyoloji laboratuarına gönderilen dış kulak yolu kültür materyallerinin sonucu retrospektif olarak hastanemiz otomasyon sistemi kayıtlarından incelendi. 34 hastanın dış kulak yolu kültüründe P.aeruginosa üremesi görüldü. Bu hastaların demografik olarak yaş, cinsiyet ve üreyen $P$. aeruginosa cinsi bakterilerin antibiyotik duyarlılıklarının değerlendirilmesi yapıldı. Aynı hastadan elde edilen $P$. aeruginosa mükerrer suşları çalışmaya dâhil edilmedi.

Dış kulak yolu kültürleri bakteriyolojik inceleme için kanlı agar, çikolatamsı agar ve Eozin Metilen Blue (EMB) agara, şüpheli mantar üremesi olan örnekler ise iki ayrı Sabouraud dekstroz agara (SDA) ekildi. Sonuçlar VITEK 2 (BioMerieux, France) antibiyogram cihazı sonuçları ve EUCAST (European Committee on Antimicrobial Susceptibility Testing) tanı kriterlerine göre hastanemiz mikrobiyoloji laboratuvarında değerlendirildi (5). Hastanemiz etik kuruluna başvurulmuş ve 11.9.2018 tarih ve TUEK 141-2018 GOKAEK/7-49 karara istinaden etik kurul onayı alınmıştır.

\section{İstatistiksel analiz}

İstatistiksel değerlendirme, SPSS 16.0 (SPSS, Chicago, IL, USA) istatistik paket programıyla yapıldı. Niceliksel sonuçlar ortalama \pm standart sapma (SS) ve kategorik sonuçlar sayı ve yüzde (\%) olarak verildi.

\section{BULGULAR}

Çalışma döneminde 73 hastadan kulak kültürü gönderildiği ve bunların 34'ünde (\%46.5) Pseudomonas aeruginosa üremesi olduğu saptandı. Bu hastaların 19 (\%55.8)'u erkek,15 (\%44.2'ü kadın, yaş ortalaması 44.9 (15-69) idi. Dış kulak yolu kültürlerinde üreyen $P$. aeruginosa suşlarının izole edildiği hastaların yaş aralığı incelendiğinde en sık olarak 51-60 yaş (\%38) aralığında üremenin olduğu saptandı (Şekil 1). Vakaların aylara göre dağılımlarının incelemesinde; en sık P.aeruginosa üremesinin yaz ve kış aylarında olduğu saptandi.

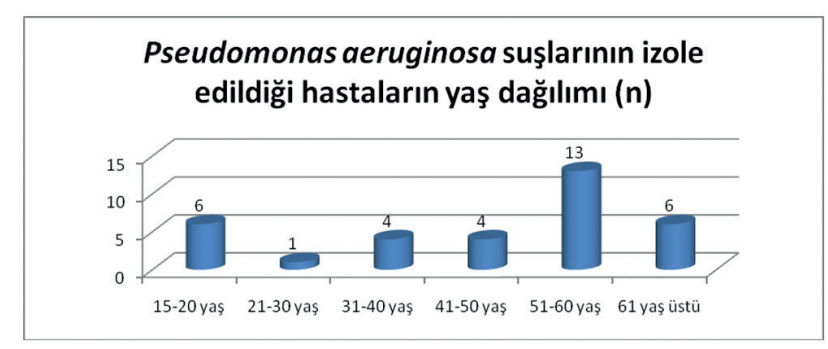

Şekil 1. Pseudomonas aeruginosa suşlarının izole edildiği hastaların yaş aralığı (n:34).

Kulak kültürlerinde üreyen P.aeruginosa suşlarının antibiyogramları incelendiğinde; en duyarlı oldukları antibiyotik sınıfının kolistin (\%100), karbapenem grubundan imipenem (\%82.3) ve meropenem (\%82.3) olduğu; en fazla direncin ise netilmisin (\%52.9), piperasilin (\%41.2), piperasilin/tazobaktama (\%41.2) ve levofloksasine (\%41.2) karşı olduğu saptand. Rutin pratikte tedavide en sık kullanılan antibiyotik olan siprofloksasine karşı ise \%61.7 oranında duyarlı olduğu belirlendi (Tablo 1). 
Tablo 1. Pseudomonas aeruginosa suşlarının antibiyotik duyarlılıklarının değerlendirilmesi.

\begin{tabular}{|l|c|c|c|}
\hline Antibiyotik & $\begin{array}{c}\text { Duyarlı } \\
(\mathbf{n , \% )}\end{array}$ & $\begin{array}{c}\text { Dirençli } \\
(\mathbf{n , \% )}\end{array}$ & $\begin{array}{c}\text { Orta duyarlı } \\
(\mathbf{n , \% )}\end{array}$ \\
\hline Sefepim & $23(67.6)$ & $11(32.4)$ & 0 \\
\hline Piperasilin & $18(52.9)$ & $14(41.2)$ & $2(5.9)$ \\
\hline $\begin{array}{l}\text { Piperasilin/ } \\
\text { Tazobaktam }\end{array}$ & $18(52.9)$ & $14(41.2)$ & $2(5.9)$ \\
\hline Seftazidim & $25(73.5)$ & $8(23.6)$ & $1(2.9)$ \\
\hline Amikasin & $21(61.7)$ & $12(35.3)$ & $1(2.9)$ \\
\hline Siprofloksasin & $21(61.7)$ & $13(38.3)$ & $0(0)$ \\
\hline Levofloksasin & $20(58.8)$ & $14(41.2)$ & $0(0)$ \\
\hline İmipenem & $28(82.3)$ & $4(1.8)$ & $2(5.9)$ \\
\hline Meropenem & $28(82.3)$ & $3(8.8)$ & $3(8.8)$ \\
\hline Gentamisin & $20(58.8)$ & $14(41.2)$ & $0(0)$ \\
\hline Netilmisin & $18(52.9)$ & $16(47.1)$ & $0(0)$ \\
\hline Tobramisin & $21(61.7)$ & $13(38.3)$ & $0(0)$ \\
\hline Aztreonam & $12(35.3)$ & $10(29.4)$ & $12(35.3)$ \\
\hline Kolistin & $34(100)$ & $0(0)$ & $0(0)$ \\
\hline
\end{tabular}

\section{TARTISSMA}

Kronik supuratif otitis media; timpanik kavite, mastoid hava hücreleri ve östaki tüpü iç yüzeyini döşeyen mukozanın kronik enflamasyonudur (6). KSOM yavaş ve sinsice seyreden, tekrarlayan veya devamlı mükopürülan akıntı ile karakterize, sıklıkla kemiklerde destrüksiyona yol açan, bazen de irreversible sekellerle sonuçlanan enflamatuar bir proçestir (7). KSOM' nın temel tedavi yöntemi cerrahi olmakla beraber konservatif tedavi de çok önem taşımaktadır. Kronik otitis media cerrahisinde öncelikli amaç devamlı kuru kalan, tekrarlayan enfeksiyonun önlendiği, perforasyonun kapand1ğ ve işitmenin düzeldiği bir kulak sağlamaktır (8). KSOM’da etken mikroorganizmaların saptanması konservatif tedavide antibiyotik kullanımının önemini ortaya koymaktadır (9). KSOM'de aerop kökenli etken patojenlerin büyük çoğunluğunu gram negatif bakterilerin oluşturduğu ve bunlar içinde de $P$. aeruginosa'nın en sık gözlendiği saptanmıştır (10).

$P$. aeruginosa insanlarda çok çeşitli enfeksiyonlara neden olan ve bu yeteneğini kolaylaştıran birçok virülans faktörü bununan bir bakteridir. Pseudomonas aeruginosa'nın KSOM'daki önemi hem biyofilm oluşumu nedeniyle tedavi yanıtsızlığına neden olması hem de çoğul antibiyotik direnci geliştirebilmesi gibi nedenlere bağlanabilir $(11,12)$. Juyal ve ark. (13) çalıșmalarında kulak kültürlerinde üreyen $P$. aeruginosa kökenlerinin \%15.5'inin beş sınıf, \%22.5'inin üç sınıf, \%9.1'inin dört sınıf antibiyotiğe dirençli olduğunu bildirmişlerdir. Aynı çalışmada en fazla kinolonlara (\%48.7), antipseudomonal penisilinlere (\%41.7), aminoglikozidlere (\%38) ve sefalosporinlere (\%34.8) karşı direnç olduğu, en az direncin ise karbapenem grubuna (\%29.4) olduğu saptanmıştır (13). Çalışmamızda da benzer şekilde üreyen $P$. aeru- ginosa kökenlerinin \%18.5'inin beş sınıf, \%24.5'inin üç sınıf, \%11.1'inin dört sınıf antibiyotiğe dirençli olduğu saptandı. P.aeruginosa, bazı antibiyotiklere karşı doğal dirençli olmasina ilaveten aktif pompa sistemleri, porin kaybı ve beta-laktamaz enzimleri gibi birçok kazanılmış direnç mekanizmalarını kullanabilmektedir. Çalışmamızın retrospektif olması nedeniyle P.aeruginosa suşlarındaki direnç mekanizmaları değerlendirilememiştir.

Pseudomonas aeruginosa tüm dünyada antibiyotik direnç oranları nedeniyle diğer sistem enfeksiyonlarında olduğu gibi KSOM vakalarında da önemini korumaktadır. $\mathrm{Bu}$ konuda yapılmış literatürde birçok çalışma mevcuttur. Nijerya'da Kazeem ve ark. (14) KOM hastalarının kulak kültürlerinde üreyen P.aeruginosa kökenlerinin, \%93.2'sinin levofloksasine, \%78.6'sinın ofloksasine, \%76.9'unun gentamisine, \%69.2'sinin seftazidime ve \%59.8'inin netilmisine karşı duyarlı olduğunu bildirmiştir. Ülkemizde yapılan çalışmalarda ise;Kuzucu Malkoç ve ark. (15) ise Pseudomonas suşlarında en düşük direncin imipenem (\%4), meropenem (\%7) ve amikasine (\%8); en yüksek direncin ise piperasilin (\%70) ve sefaperazona (\%60) karşı olduğunu bildirmiştir. Özkan ve ark. (16) ise otit etkeni olan Pseudomonas suşlarındaki direnç oranlarını imipeneme (4\%), meropeneme (7\%) ve amikasine $(8 \%)$ oranında ve en yüksek direncini piperasilin (70\%), sefoperazon (60\%) ve tikarsilin klavulanik aside (\%54) karşı olduğunu saptanmıştır. Aynı çalışmada siprofloksasin direnci \%25 oranında bildirilmiştir (16).

Çalışmanın retrospektif olması ve vaka sayısının az olması çalışmamızın kısıtlılığını oluşturmaktadır .

Sonuç olarak, Kronik süpüratif otitis mediada dış kulak yolundan alınan kültürlerde en sık üreyen gram negatif bakterinin Pseudomonas olduğu bilinmesi ve üreyen patojenin antibiyogram duyarlılıklarının saptanması gerek enfeksiyona bağlı komplikasyonların önlenmesi gerek ise KSOM’nın asıl tedavisi olan cerrahiye başlanma süresini kısaltacaktır. Etken patojenin duyarlılık paternleri zaman içerisinde değişiklik gösterebileceğinden, komplikasyon gelişme riskinin azaltılması, zaman ve maliyet kaybınının en aza indirgemesi amaçları ile antibiyotik duyarlılıkları takip edilmeli ve güncel verilere göre düzenlenmelidir.

Çıkar çatışması ve finansman beyanı: Bu çalışmada çıkar çatışması yoktur ve finansman desteği alınmamıştır. 


\section{KAYNAKLAR}

1. İncesulu A. Kronik Süpüratif Otitis Media. Turkiye Klinikleri J Surg Med Sci 2005;1(7): 66-70.

2. Poorey VK, Thakur P. Clinico microbiological evaluation and antibiotic susceptibility in cases of chronic suppurative otitis media. Indian J Otol 2015;21(2):107-110.

3. Prakash M, Lakshmi K, Anuradha S, Swathi GN. Bacteriological profile and their antibiotic susceptibility pattern of cases of CSOM. Asian J Pharm Clin Res 2013;6(3):210-212.

4. Gellatly SL, Hancock RE. Pseudomonas aeruginosa: New insights into pathogenesis and host defenses. Pathog Dis 2013;67(3):159-173.

5. The European Committee on Antimicrobial Susceptibility Testing. Break point tables for interpretation of MIC sand zone diameters. http://www.eucast.org)

6. Qureishi A, Lee Y, Belfield K, Birchall JP, Daniel M. Update on otitis media-prevention and treatment. Infect Drug Resist 2014;7:15-24.

7. Ünal R, Güney E, Şeşen T, Gür Ö. Kronik Süpüratif Otitis Mediada Bakteriyolojik Araştırma. Ondokuzmayıs Üni Tıp Fak Derg 1989; 6(2):195-204.

8. Öktemer T, Kemaloğlu Y, Özbilen S, Tutar H. Kronik Otitis Media Cerrahisinde Greft Başarısını Etkileyen Faktörler. OTD 2016;38(3):46-54.

9. Altuntaş A, Aslan A, Ünal A, Eren N, Titiz A, Nalça Y. Kronik Süpüratif Otitis Media'da izole edilen mikro organizmaların ciprofloxacin ve ofloxacine duyarlılıkları. K.B.B. ve Baş Boyun Cerrahisi Dergisi 1995;3:102-104.

10. Gül C, Kurnaz A, Turhan V, Öncül O, Pahsa A. Kronik Otitis Medialı Hastalarda Orta Kulak Kültüründe Üreyen Mikroorganizmalar ve Antibiyotik Duyarlılıkları. Kulak Burun Bogaz Ihtis Derg 2006;16(4):164-168.

11. Ballok AE, O'Toole GA. Pouring salt on a wound: Pseudomonas aeruginosa virulence factors alter $\mathrm{Na}+$ and $\mathrm{Cl}-$ flux in the lung. J Bacteriol 2013;195(18):4013-4019.

12. Durmaz S, Özer TT. Klinik örneklerden izole edilen Pseudomonas aeruginosa suşlarında antibiyotik direnci. Abant Med J 2015;4(3):239-242.

13. Juyal D, Sharma M, Negi V, Prakash R, Sharma N. Pseudomonas aeruginosa and its sensitivity spectrum in chronic suppurative otitis media: A study from Garhwal hills of Uttarakhand state, India. Indian J Otol 2017; 23(3):180184.

14. Kazeem MJ, Aiyeleso R. Current bacteriological profile of chronic suppurative otitis media in a tertiary facility of Northern Nigeria. Indian Journal of Otology 2016; 22(3):157-161.

15. Kuzucu Malkoç H, Uyanık MH, Aktaş O, Ayyıldız A. Dış Kulak Yolu Kültür Sonuçlarının Değerlendirilmesi. Eurasian J Med 2006; 38(3): 85-88.

16. Özkan Ö, Uslu H, Vural Keleş D, Mutlu V, Bingöl F, Yaşar M,et al. Kronik Otitli Hastalarda Antibiogram Duyarlılık Sonuçları. Tip Araştırmaları Derg 2015: 13(2):70-75. 